\title{
Estanislao Zeballos: a história jamais escrita da Guerra da Tríplice Aliança ${ }^{1}$
}

\author{
Estanislao Zeballos: The Triple Alliance War never written History \\ Estanislao Zeballos: La Históriajamais escrita de la Guerra de Tríple Alianza
}

Mário Maestri *

\section{Resumo}

A partir do fundo Estanislao Zeballos, do Arquivo Juan Bautista Gill Aguinaga, discute-se o sentido da trajetória daquele homem político argentino e sua relação com a guerra contra o Paraguai (1865-1870). Exploram-se as razões da não conclusão de sua proposta de produzir a história geral do conflito. Analisa-se a documentação produzida por ele em visitas ao Paraguai e de seu registro do desenvolvimento de espírito revisionista pró-lopizta no país. Abordam-se os problemas postos pelos depoimentos orais de protagonistas, diretos e indiretos, sobre a guerra.

Palavras-chave: Estanislao Zeballos. Guerra do Paraguai. História e memória.

\section{Estanislao Severo Zeballos: homem de política, de cultura e de ação}

Estanislao Severo Zeballos nasceu em Rosario, Santa Fé, em 1854, quando a Argentina começava a viver plenamente as contradições entre unitários e federalistas, após a deposição de Juan Manuel de Rosas (17931877), em Monte Caseros, em 3 de fevereiro de 1852. Ele seria conhecido no país como prócer político da Geração de 1880, que animou a República Conservadora e Oligárquica (1880-1816), após a vitória do unitarismo liberal-mitrista sobre o federalismo provincial, na batalha de Pavón, em 17 de setembro de 1861. Político e intelectual de ampla atua-

Doutor em História pela Université Catholique de Louvain, Bélgica. Professor titular do Programa de Pós-Graduação em História da Universidade de Passo Fundo, Brasil. E-mail: maestri@via-rs.net

\footnotetext{
Recebido em 04/05/2015 - Aprovado em 25/05/2015 http://dx.doi.org/10.5335/hdtv.15n.2.4993
} 
ção, sua influência extrapolou sua época, sentida ainda hoje na Argentina.

No período 1866-1872, com dificuldades econômicas familiares devido à morte do pai, Estanislao Zeballos dedicou-se aos estudos, como bolsista, no Colégio Nacional de Buenos Aires, fundado por Bartolomé Mitre (1821-1906) para conquistar a juventude provincial à nova ordem liberal-unitária. Em 1870, com dezesseis anos, ainda estudante, necessitando trabalhar para sustentar-se, ingressou como "segundo notário" no destacado diário La Prensa, de Buenos Aires, liberal-conservador, fundado no ano anterior, do qual seria redator e diretor.

Em 1874, Zeballos licenciou-se e foi doutorado em Direito pela Universidade de Buenos Aires, onde ensinou e foi decano de 1918 a 1919. Nesse último ano, abandonou aquela posição de destaque pressionado pelo movimento da Reforma Universitária (1918). Foi líder pastoril-latifundiário, deputado provincial e nacional, presidente da câmara nacional, diplomata, três vezes ministro dos assuntos exteriores (DALLA-CORTE, 2011, p. 25). Com estudos institucionais em Ciências Exatas, foi ensaísta de sucesso, escrevendo, em 1878, La conquista de quinze mil léguas: estúdio sobre la traslación de la fronteira sul de la República al rio Negro. O livro fora encomendado e financiado pelo general Julio Roca (1843-1914), então ministro de Guerra e Marinha, para apoiar a campanha militar proposta contra os poucos milhares de índios pampas para conquistar seus territórios (ZEBALLOS, 1998, p. 22; ÉBÉLOT, 2008, p. 195-235; RODRÍGUEZ, c2015).

Em 1872, com dezoito anos, Zeballos participou da fundação da Sociedad Cientí- fica e, em 1879, um ano após a conclusão da Guerra del Desierto, do Instituto Geográfico Militar (a seguir Instituto Geográfico Nacional). Nesse, a geografia andava de mãos dadas com a expansão dos territórios e da economia mercantil dos Estados nacionais, e no caso da Argentina, extensão dos territórios em direção ao sul e, se possível, do oeste. Em 1901, integrou a atual Academia Nacional de História da Argentina. Pensador e político positivista, nacionalista e conservador, defendeu a superioridade de estirpe argentina imaginada, de lídima origem hispânica e europeia, e de seu pretenso destino diretor quanto aos vizinhos nacionais, inferiores. Foi "intelectual orgânico" do programa de construção-expansão territorial apoiado em latifúndio, imigração europeia, colonização agrícola, exportações, que tinha, na Europa liberal e ilustrada, o paradigma cultural (LACOSTE; ARPINI, 2002, p. 125-146).

Zeballos escreveu precocemente ensaios sobre paleontologia, arqueologia e antropologia, disciplinas então semidesconhecidas na Argentina, abraçando, mais tarde, a estranha teoria do portenho Florentino Amighino (1854-1911) de nascimento da humanidade no pampa argentino - "Homus pampeanus" (LACOSTE; ARPINI, 2002, p. 132). Em 1898, fundou, financiou e dirigiu, até a morte, a Revista de Derecho, Historia y Letras, locus de expressão de suas posições político-ideológicas (SÁNCHEZ, 2009, p. 224). Desde jovem, preocupou-se com a disputa entre a Argentina e o Brasil pela hegemonia regional. No Brasil, é conhecido, sobretudo, pela militância, quando ministro do exterior, de 1906 a 1908, pelo armamento argentino, em vista de conflito com o Brasil que julgava próximo e desejável. 
Nos países vizinhos, Zeballos foi visto como defensor da refundação - ampliada - do vice-reinado do Prata, que assombrou sempre o Estado brasileiro, que temia que a grande nação lhe fizesse contraponto no Prata. No Brasil, foi acusado de manipular telegrama cifrado do barão de Rio Branco (18451912) para defender suas posições belicistas (HEINSFELD, 2008). A leitura incorreta do documento teria contribuído para sua queda do governo, ao ser questionado por seus opositores, que divergiam de seu militarismo (LACOSTE; ARPINI, 2002, p. 126).

Registre-se em defesa de Zeballos que, então, o governo brasileiro encomendara na Inglaterra reaparelhamento faraônico da esquadra, que a colocou entre as mais poderosas do mundo. Esquadra que viveu, em novembro de 1910, a maior sublevação de marinheiros do século $X X$, em prol do fim da chibata e de melhorias profissionais (MAESTRI, 2015). Como ministro, Zeballos militou também pelo armamento em relação ao Chile, que, para ele, ocuparia territórios que caberiam à Argentina (LACOSTE; ARPINI, 2002, p. 125-146).

Estanislao Zeballos foi escritor desbordante, autor de centenas de artigos, ensaios e livros sobre agricultura, antropologia, direito, economia, ficção, geografia, política, etc. Em cinco tomos, sua mais ambiciosa obra, editada quando gozava de prestígio mundial como jurista, traduzida ao francês, tratou de La nationalité au point de vue de la législation comparée et du droit privé humain (ZEBALLOS, 1914-1919). Em 1912, ingressou no prestigioso Institut de Droit International, e, consagrado internacionalmente, em 1923, foi eleito presidente da International Law Association (LACOSTE; ARPINI, 2002, p. 125-146).

\section{Estanislao Zeballos: uma história prometida}

Sem jamais destacar-se pela produção historiográfica propriamente dita, desde 1884, Zeballos anunciou, por décadas, até a morte, a intenção de escrever história geral da Guerra da Tríplice Aliança contra o Paraguai (1864-1870). Seu sucesso político e econômico permitiu-lhe produzir e reunir ampla e variada documentação sobre o tema - livros, documentos, mapas, entrevistas, etc. Ao morrer, sua biblioteca pessoal possuiria 30 mil volumes. Em 1887 e 1888, empreendeu duas importantes expedições à província de Corrientes, ao sul do Paraguai, e a Asunción, visitando locais de combate e entrevistando dezenas de argentinos, uruguaios, franceses, ingleses e, sobretudo, paraguaios, protagonistas ou testemunhas do conflito (BREZZO, 2006). Com o hábito de apoiar o que escrevia em dados obtidos sur place, realizara expedições ao interior da Argentina, sobre as quais produziu ensaios de sucesso (RODRÍGUEZ, 2015). Nos anos seguintes, manteve correspondência para obter dados para a empreitada paraguaia. ${ }^{2}$

Não conhecemos entrevistas e correspondências de Zeballos com políticos e militares brasileiros, apesar do caráter central desempenhado pelo Império no conflito. As razões parecem óbvias. Naquele então, a Argentina e o Brasil, os dois grandes ex-aliados, disputavam a hegemonia sobre o sul da América e sobre a nação vencida, que o governo brasileiro apoiava contra exigências argentinas pós-conflito, que dizia excessivas (CERVO; BUENO, 1986, p. 30-35; ESTEVES, 1996, p. 121-125). Eram questões 
que preocupavam desde muito o intelectual e político argentino, que se destacava como defensor do confronto com o Brasil, se necessário, armado.

Apesar do significativo esforço de documentação, ao morrer, em 4 de outubro de 1923, aos 69 anos, em Liverpool, na Inglaterra, durante viagem ao exterior, o escritor célebre, habilidoso e infatigável quase nada publicara sobre a guerra terrível!

\section{Razões de um projeto}

Compreende-se a disposição de Zeballos, em meados de 1880, de empreender tal iniciativa historiográfica. Em 1870, ao findar a guerra, ele preparava-se para completar os 16 anos. Como os jovens de sua geração, acompanhara em casa, na escola e nas ruas fatos que galvanizaram e dividiram a sociedade argentina. Apesar das raízes federalistas de sua família, como tantas outras, ela foi tomada de furor patriótico-unitarista antiparaguaio. Em 1865, o menino Estanislao emocionara-se com o anúncio do conflito, apesar de confessar que, mesmo sendo "estudiante de geografía", ignorava se o Paraguai "era de este o de otro mundo". Como tantos jovens, decidira-se arrolar-se e partir para o front. Foi frustrado na precoce carreira militar pela severa tunda propiciada pelo pai, ex-militar, que - ele mesmo revelaria, já adulto - esfriara suas "ideas patrióticas!" (DE MARCO, 2009, p. 222-224). Mais tarde, referiu-se a viagem que teria feito, em 1869, impressionado pela guerra, à fantasmagórica capital paraguaia. Tradição registra 1868 como a data da viagem e seu engajamento, aos 15 anos, como tenente de infantaria imperial, relato pouco crível. Zeballos seria econômico em informações sobre essas propostas experiências no Paraguai, que exigem comprovação documental (DALLA-CORTE, 2011, p. 20).

Escrever uma história geral da guerra da Tríplice Aliança tratava-se de operação intelectual em consonância com a disposição de jovem político e pensador que abraçara a causa nacional portenha vencedora, rompendo com as raízes federalistas da família, da cidade natal e de sua província. Com 30 anos, em plena ascensão, Zeballos lutava para ampliar o espaço e relações que gozava no mundo político, social e intelectual argentino dominante. Esforçava-se para conquistar a posição que as relações e raízes crioulas dos seus sobrenomes sugeriam, mas que a falta de recursos familiares dificultava. A escritura de uma história geral da guerra grande era necessária. Oito anos após o fim da ocupação militar do Paraguai, abundavam as histórias rápidas dos sucessos e os relatos de ex-combatentes argentinos e brasileiros, escritos antes e após o fim do conflito, não raro de circulação local ou regional. ${ }^{3}$

Então, sobretudo, havia a ampla História da Guerra do Brasil contra as Repúblicas do Uruguay e Paraguay, em quatro volumes, de Francisco Felix Pereira da Costa, com ampla abordagem da influência da questão oriental nos sucessos (COSTA, 1870-1871). Na Argentina e no Brasil, o trabalho referencial seguia sendo do major inglês George Thompson, simpático ao Paraguai, antipático ao Império do Brasil e crítico a Solano López, a quem servira lealmente até a rendição de Angostura, em 30 de dezembro de 1868 (THOMPSON, 1869). 
Porém, em 1883 e 1884, surgiam os valiosos Recuerdos de la guerra del Paraguay, do veterano militar José Ignacio Garmendia (1841-1921) (GARMENDIA, 1883-1884.). No Brasil, o primeiro trabalho mais ambicioso, História da guerra do Paraguai, foi publicado em 1897, em três volumes, pelo coronel sul-rio-grandense José Bernardino Bormann (1844-1819), dedicado aos companheiros de combate (BORMANN, 1897). Também no Brasil, em 1902, vinha a lume a história da guerra do prussiano Louis Schneider (18051875), pró-imperial, anotado pelo barão do Rio Branco, de fumos oficialistas (SCHNEIDER, 1902).

\section{Promessa não cumprida}

A operação proposta por Zeballos cumpria uma quase necessidade de Estado e aproximava e estreitava as relações do jovem com os pro-homens argentinos que haviam vencido a guerra e dirigiram a nação, assim como dos protagonistas uruguaios e paraguaios do conflito, derrotados, mas se acomodando aos vencedores. Eram laços pessoais importantes para a carreira política e diplomática que já deslanchara. Décadas mais tarde, Zeballos teria se tornado hiperlatifundiário no Chaco Boreal, remunerado pela mediação do tratado bolivariano-paraguaio de 1907 (DALLA-CORTE, 2006, p. 105-121). Por décadas, o político e intelectual correspondeu-se e entrevistou-se com Mitre, não raro semanalmente, facilitando-lhe o ex-presidente o acesso parcial aos seus magníficos arquivos, contando certamente que Zeballos redigisse versão mitrista não oficial da história que ele protagonizara. Mitre foi autor de importante obra historiográfica, na qual se destacam Historia de Belgrano y de la Independencia Argentina (1889) e Historia de San Martín y de la Emancipación Sudamericana, em três volumes $(1887,1888,1890)$. Em 1874, Zeballos participara do levante fracassado propiciado pelo ex-presidente. Agora, prometia colocar a pena ao serviço da construção da hagiografia mitrista (DE MARCO, 2009, p. 15).

Contudo, ao morrer, quase trinta anos após a decisão sempre mantida, Zeballos juntara vastíssima documentação sem publicar quase nada sobre o conflito, à excessão de artigo sobre a batalha do Riachuelo. Não foram encontrados nem mesmo rascunhos dos inúmeros livros que comporiam o trabalho prometido. Portanto, resta-nos apenas conjeturar sobre as razões e eventuais consequências desse paradoxal fiasco. O projeto anunciado, portentoso e ambicioso, pretendera-se definitivo: onze volumes, mais um anexo cartográfico, segundo o dito pelo autor em correspondência a Mitre. Em verdade, ao registrar o plano de trabalho, propôs escrever um tomo especial sobre os sucessos ocorridos "dentro do Paraguai" quando da guerra - o que não foi feito, plenamente, até hoje. Assim, a obra comportaria treze volumes (BREZZO, 2006).

Quando anunciou a obra magnífica, Zeballos já produzira livros de sucesso, em geral entre o ensaísmo e a fiç̧ão, alguns em continuação ao livro encomendado pelo general Roca. Aqueles foram os seus anos de maior produtividade bibliográfica. Entre outros trabalhos, escreveu Episodios en los territorios del sur (1879), Descripción amena de la República Argentina, em três volumes $(1881,1883,1888)$, Callvucurá y la dinastía de los piedra (1884), Painé y la dinastía de los zorros (1886), Relmu, 
reina de los Pinares (1888). Escritor experiente, não tinha tradição na produção historiográfica, que exige enorme dedicação, sobretudo tratando-se de obra de tal dimensão, a ser escrita com a historiografia da guerra então gatinhando. Tinha autoridade e recursos para fazer entrevistas, pedir depoimentos, contratar copistas, etc., mas o tempo lhe seria curto, visto o crescente sucesso como jornalista, político, ministro, diplomata, professor, advogado, estancieiro, etc. E o Paraguai seria um entre outros projetos bibliográficos.

Homem maduro e jurista consagrado, redigiu estudo jurídico de fôlego, e não a obra prometida sobre a guerra. Talvez lhe dificultasse a escritura, a consciência de que, sobretudo após Curupayty, em setembro de 1866, e o fortalecimento dos motes no interior da Argentina, a guerra fora uma operação querida e levada ao fim, principalmente, pelo Império do Brasil (POMER, 1986). O certo é que a obra não deslanchara. Dezoito anos mais tarde, o político e historiador paraguaio Manuel Dominguez (1868-1935) escrevia, talvez descrendo na promessa: "Termine, por Dios, aquella historia de la guerra del Paraguay, assunto digno de sua brillante pluma" (BREZZO, 2006, p. 18).

\section{0 plano geral e o sentido da obra magnífica}

Na Argentina, um trabalho de grande amplitude - seis tomos e anexos cartográficos - foi produzido em 1933, meio século após Estanislao Zeballos propor-se à tarefa, pelo coronel cordobês Juan Beverina (1877-1943), militar com tradição na historiografia castrense argentina (BE-
VERINA, 1933). Em 1934, o general brasileiro Augusto Tasso Fragoso (1869-1945), também enfronhado naquela arte, e dispondo de posição de destaque no aparato estatal brasileiro, lançou a exaustiva História da guerra entre a Tríplice Aliança e o Paraguai, em cinco volumes (FRAGOSO, 1934; MAESTRI, 2012). Os seis volumes de Beverina somados aos cinco de Fragoso não perfaziam os doze ou treze prometidos por Zeballos! É quase fantasia realizar prognósticos sobre o valor e a orientação de obra jamais escrita. Porém, sua formação, a visão de mundo, a militância política, a intimidade com Mitre, o plano de trabalho, tudo sugere que, provavelmente, obedeceria aos cânones da historiografia inspirada pelo centralismo estatal argentino. Hipótese corroborada pelas entrevistas que produziu, pois há traços de sua intencionalidade nos depoentes selecionados, temas abordados, perguntas postas, orientações e transcrições das entrevistas, já que raramente reproduzia literalmente os depoimentos.

Zeballos propôs dedicar o tomo inaugural da obra monumental à história e à sociedade paraguaia. Se é correta a informação do representante oriental em Asunción, quando ali chegou o "notable escritor", em abril de 1888, ele dedicaria "especial atención a los governos de Francia y López", reunindo "en un libro la terrible historia de las tiranías sufridas" pelos paraguaios (BREZZO, 2005, p. 226). O que sugere resgate da crítica tradicional portenha ao antiliberalismo paraguaio, retomada após a guerra pela historiografia (MAESTRI, 2009). O segun- 
do tomo abordaria os sucessos pregressos à guerra de 1864-1870, desde a Revolução de Maio de 1810. No plano geral de trabalho, não há referência ou destaque à invasão da República do Uruguai, por Venancio Flores, apoiada por Bartolomé Mitre e, a seguir, pelo Império do Brasil, tida como causa fundamental do início do conflito (HERRERA, 1927). Os nove livros seguintes abordariam cronologicamente os fatos bélicos.

Tratava-se de plano geral tradicional de história político-diplomática-militar, sem inovações temáticas, com excessão do tomo proposto sobre o Paraguai durante o conflito. O que sabemos sugere também explicação do passado a partir dos grandes protagonistas. Em carta ao padre paraguaio Fidel Maíz (1828-1920), Zeballos afirmara que buscava "la verdad, sin partido tomado previamente, dispuesto a amparar com ella a quien la mereça". ${ }^{4} \mathrm{Ou}$ seja, definir os vilões e os heróis, os protagonistas e os antagonistas, como normal na ciência historiográfica positivista. Os depoentes de Zeballos eram os grandes protagonistas do conflito. No Paraguai, Bernardino Caballero, o padre Fidel Maíz, o dirigente legionário Segundo Decoud, Pedro Duarte, entre outros. Na Argentina, mesmo sendo Bartolomé Mitre o depoente por excelência, consultou outros oficiais militares (ou seus familiares), Emilio Mitre, Luis María Campos, Ignácio Garmendia, Candido López, entre outros. No Uruguai, contatou Juan José de Herrera, a família de Venancio Flores, Justiniano Salvañach, etc. Alguns europeus foram ouvidos, mas, segundo parece, nenhum brasileiro protagonista daqueles feitos.
Fiel à tradição positivista, mesmo entrevistando algumas mulheres, Zeballos não se preocupou com a voz feminina, mesmo das classes proprietárias. Ele se opôs, sempre, ao voto da mulher, pois, bom positivista, via como papel feminino "formar niños y darles una 'conciencia nacional' en el seno del hogar" (DALLA-CORTE, 2009, p. 23). Ainda que muito breve, o depoimento de Concepción Domecq de Decoud deixa-nos entrever a importância dessa voz até há pouco desprezada. ${ }^{5} \mathrm{Em} 1893$, o sul-rio-grandense J. Montenegro, estudioso do conflito, publicou em português as memórias da prisioneira francesa Dorothéa $\mathrm{Du}-$ prat de Lasserre, escritas, em 1870, a pedido de oficial imperial (LASSERRE, 1893). Como os autores de sua época, Zeballos ignorou o depoimento dos abundantes populares que viveram e lutaram a guerra no semianonimato, protagonistas coletivos e individuais do conflito geral.

Ao registrar o depoimento de informadores socialmente não excelentes, assinalava que eram homens excepcionais, para resgatar o valor do depoimento. Em fins de 1919, quando combatia a reforma universitária, Zeballos declarou:

Los hombres de Estado son cérebros superiores; el vulgo tiene el dever de pensar como los hombres superiores y no los hombres superiores como el vulgo (LACOSTE; ARPINI, 2002, p. 132).

São raros os registros de fatos, hábitos e tradições do quotidiano da guerra. Ao anotar, com sua singular competência narrativa, um relato popular fantasmagórico sobre a guerra, entrevemos o valor do que deixou de registrar. ${ }^{6}$ 


\section{0 tirano como culpado}

Os registros de Zeballos sugerem um viés interpretativo do conflito segundo a visão liberal-patriótica mitrista. No plano de trabalho, refere-se aos paraguaios como "enemigos" e a López, como "tirano". As visões das gerações de 1870 e 1880 sobre a guerra, sucesso cardinal na formação do Estado unitário argentino, eram no essencial concorrentes. Seguia-se propondo o confronto como a luta entre a barbárie e a civilização, entre o centro e a periferia, causada pela ambição do ditador despótico contra quem fora feita a guerra, exclusivamente. Nos depoentes, Zeballos procura a confirmação dessa tese.

Durante a guerra, aquela retórica justificadora, que apresentava Solano López (1862-1870) como o responsável exclusivo do conflito - lopizmo negativo -, fora abraçada pelas facções paraguaias liberais que dirigiram o país imediatamente após o conflito (ROLÓN, 2011). Após o fim da guerra, ela fora funcional aos quadros (paraguaios e estrangeiros) do aparato administrativo militar e político lopizta. O médico inglês Guillermo Stewart lembrava que, após a derrota, "nosotros ingleses que estábamos a su lado (de López), teníamos vergüenza de habernos manchado sirviendo a tal monstruo". Ele fora membro do círculo restrito do mariscal e pudera sempre abandonar sua posição. Em seu livro, de 1869, Thompson, que servira fielmente nas tropas paraguaias, racionalizara sua participação no conflito responsabilizando Solano López (THOMPSON, 1869). ${ }^{7}$

Aquela explicação era coerente com visões cultas da época, que viam os grandes homens como demiurgos da história. Sobre as costas largas de López acomodaram-se inicialmente as elites paraguaias vencedoras e vencidas, que administraram o país destruído e refundado na tradição liberal-mercantil-latifundiária. Fazendo da nécessité ver$t u$, reconheciam os bons serviços aliancistas, ao pôr fim ao reino do despotismo no Paraguai. Os vencidos reivindicavam apenas o reconhecimento da dignidade e o heroísmo do combatente paraguaio. Em 1888, dueña Juana, viúva do general Francisco Isidoro Resquín (1823-1882), alegrava-se que o político argentino pretendesse "historiar nuestra guerra nacional, separando lo que pertenece a los caprichos de un hombre (Solano López) y al valor legendario de un pueblo". ${ }^{8}$ Seu esposo integrara o círculo militar paraguaio máximo durante a guerra.

Ao entrevistar legionários e ex-membros da administração paraguaia, Zeballos recebeu a confirmação que procurava (AGUINAGA, 2011). A culpa da guerra e da derrota teria sido de López, definido como homem desprezível, malévolo, falso, covarde. Suas próprias raízes familiares não o recomendariam. Zeballos pediu ao padre Fidel Maíz, "datos sobre el carácter y origen de los López". Para gáudio do argentino, crente da determinação do homem pela raça, o padre afirmou que, por parte do avô paterno, a família López "no era de la raza blanca", distinguindo-se pelos membros "tétricos y ensimismados", opostos por "antagonismo inconciliable".

Sobre os tribunais de sangue, tema central da narrativa antilopista, os depoentes foram também unânimes em afirmar que criam que a conspiração jamais existira, tese 
da narrativa liberal-platense forte até hoje. Assim dissera, entre outros, Patricio Escobar, que lembrava ter pedido uma vez ao mariscal pela vida "de un inocente" - haveria, então, culpados ${ }^{10}$ A conspiração seria produto da imaginação e sede de sangue de Solano López. Nesse quesito, destaca-se o depoimento do tortuoso padre Maíz, acusado de protagonizar aqueles sucessos, aproveitando-se deles para tentar alcançar a posição máxima na Igreja paraguaia. Em longa carta, afirma que os "procesos [...] eram fabricados bajo la imediata inspiración de López". O tirano teria as sentenças "preconcebidas" e assinalava nas listas dos julgados os que deveriam morrer. ${ }^{11}$

Inquirido sobre a conspiração, o padre Maíz foi viscoso como uma enguia. Limitou-se a propor que acreditava que não tivesse existido: "Yo creo que no ha existido". A seguir, confirmou a conspiração, obliquamente, ao assinalar que, após o cerco de Humaitá e a crença na perdição do mariscal, era "lógico que algunos vecinos principales" se preocupassem com "la dirección de los intereses propios y generales", "poniéndose de acuerdo o intentándolo con los brasileros". ${ }^{12}$ Aquela fora a justificativa de Benigno, ao ser inquirido pelo irmão, em San Fernando, sobre as propostas de entrega de Asunción à esquadra imperial, em fevereiro de 1868.

- Señor, como no hemos temido más noticias de Ud. o del ejército [...], había creído llegado el momento de pensar y tomar algunos resolución tendente a salvar nuestras personas y neutros intereses (CENTURIÓN, 2010, p. 309).

Ou seja, entrar em confabulação com o inimigo!
Para o sacerdote, López teria empreendido os processos ao saber precisamente das tentativas ou contatos com os aliancistas. ${ }^{13}$ Fidel Maíz denunciou o comportamento do mariscal, algoz dos irmãos e torcionário da própria mãe. Mas sugeriu a possibilidade da materialidade do plano de envenenamento do mariscal. "Mi madre, no hay para que negar cuando ya está todo descubierto" - teria declarado, segundo ele, Venancio, em Caraguatay. ${ }^{14}$

\section{Uma documentação inestimável - a radiografia de uma época}

O Fundo Estanislao Zeballos, do Arquivo Bautista Gill Aguinaga, a ser publicado, é formado por cartas isoladas, depoimentos escritos pelos autores, cópias de documentos, entrevistas realizadas e transcritas por Zeballos, etc. Trata-se de documentação multifacetada de valor singular, que se abre a múltiplas leituras e interpretações, colocando igualmente não poucas novas questões. Desse material, destaca-se a longa entrevista com o coronel Pedro Duarte, que expõe sua versão direta sobre a batalha de Yatay, na Argentina, diante de Uruguaiana, em 17 de agosto de $1865 .{ }^{15}$ Como complexo documental, valoriza-se singularmente pelo inestimável registro do momento de transição cultural, ideológica e política da sociedade paraguaia, nos anos 1887-1888, quando da produção da maioria das entrevistas realizadas.

Enquanto Zeballos avançava, em Asunción, sua enquete sobre a guerra, afloravam no Paraguai fenômenos políticos e culturais que assentavam raízes nas entranhas da me- 
mória e das experiências populares. Ocorreu um processo complexo e contraditório, apresentado, em geral, de forma mecanicista, redutora e ideológica, como mero produto de conspiração nascida de interesse material (reivindicações fundiárias de Enrique Solano López) e de ambição política do antigo alto-comando militar (coloradismo) (PAGNI; CESARETTI, 2007). Ainda que esses e outros interesses e pretensões procurassem eventualmente orientar, manipular e se servir daquele processo singular, é simplismo inaceitável explicar fenômenos sociais ou culturais profundos a partir de motivações secundárias, superficiais e contingentes. Aquelas forças teriam se expressado, sem a influência das referidas determinantes superficiais, ainda que com configurações diversas. Ao referir-se ao que propôs como ressurgência do atavismo guarani, Zeballos assinalava as importantes metamorfoses em curso nas, como diríamos hoje, representações historiográficas e culturais paraguaias organizadas e racionalizadas do grande conflito. Com sensibilidade, anunciava o nascimento do lopizmo positivo. "Hay en la Asunción indiscutiblemente un partido lopista, que si hoy no tiene vida activa, tiene culto a la memoria del que otros paraguayos [...] llaman Tigre". Seguia Zeballos no registro daquele momento de transição: "Hay retratos (de Solano López) en todas las casas de sus amigos más o menos mal hechos". ${ }^{16}$

O depoimento do capitão de fragata paraguaio Pedro Gill, veterano da guerra, liberal e furibundo antilopista, referiu-se ao forte sentimento popular. Zeballos perguntou a ele: "desde cuando había empezado López a ponerse malo". Sua resposta foi ca- bal: "¡Siempre fue malo!". E completou desanimado: "Sin embargo ¡lo quieren!". ${ }^{17}$ Mais do que uma invenção, o lopizmo positivo foi um fenômeno social que transcendeu o próprio personagem histórico no qual se fixava.

A visão geral de Zeballos sobre a guerra aflora aqui e lá, ao comentar e transcrever as entrevistas e documentos que reúne. Variariam apenas os argumentos que reafirmavam as narrativas ideológicas de Mitre e Domingos Faustino Sarmiento (1811-1886) de luta entre civilização e barbárie, entre campo e cidade, entre centro e periferia. Corroborando aquelas visões, Zeballos assinala a força do barbarismo guarani que, segundo ele, aflorava após a guerra, por além de frustrados ensaios de civilização. Zeballos traça o retrato do ex-líder legionário José Segundo Decoud, que, para ele, procurava negar suas raízes nacionais. Propôs que, apesar de não se crer um

[...] paraguayo en sus hábitos y maneras, la sangre (guarani) pugna con el refinamiento, $y$ sus botines de cabritilla con empeine o capellada de seda color Bismarck claro, dicen desde lejos, que es un paraguayo quien lo lleva. ${ }^{18}$

Para Zeballos, eram raízes que ressurgiam após a planta ter sido aparentemente extirpada: "Se nota que las nuevas generaciones de paraguayos vienen con ideas reaccionarias en favor del pasado bárbaro de este país". ${ }^{19}$

\section{Uma questão de raça}

Zeballos não explicava, a partir da história e da sociologia, o fenômeno que descrevia. Apoiando-se no "racismo positivista" e no "darwinismo social", acreditava que tudo se deveria à força transcendental 
da raça. "Es una ley de la existencia y un fenómeno fisiológico que se explica. La pureza de la sangre guaraní predomina todavía y ahoga los gérmenes nuevos" ${ }^{20}$ Ele menosprezava as "razas 'inferiores'" e propunha a criação de nova raça e de nova civilização argentinas, surgidas da confluência do imigrante europeu com os extratos crioulos de raízes espanholas (SÁNCHEZ, 2009, p. 230).

Em 1915, Zeballos escrevia no verbete relativo à população argentina, da célebre enciclopédia El tesoro de la juventud:

El carácter de esta población (Argentina) es enteramente europeo, pues, como ya dijimos, la raza blanca [sic] ha fecho desaparecer, por absorción [sic], a los indios y a los mestizos (LACOSTE; ARPINI, 2002, p. 131).

Visões de mundo correntes na época entre a intelectualidade elitista conservadora latino-americana.

No Brasil, em 1902, Euclides da Cunha (1866-1909) publicara a sua obra referencial, Os sertões: a campanha de Canudos, em que, impregnado pelas visões do racismo pretensamente científico e do determinismo geográfico e climático, anunciava e festejava o proposto próximo desaparecimento das raças caboclas brasileiras, historicamente superadas, segundo ele, pelas levas de imigrantes europeus que inundariam o Brasil (CUNHA, 1911).

Apesar da explicação desvairada e da qualificação ideológica do fenômeno, Zeballos acertava ao anunciar a ruptura na hegemonia ideológica imposta pelos aliancistas, no que se referia ao conflito: "Evidentemente el Paraguay va a pasar por las tormentas de la demagogia guaraní semi-civilizada" ${ }^{21}$
Os Estados signatários da Tríplice Aliança propuseram que a guerra não fora contra o país e os paraguaios, mas contra Solano López, ditador sanguinário responsável pelo conflito, pela mortandade, destruição e perdas territoriais, indenizações, etc. Essa tradição chocava-se contra o bom senso e, sobretudo, com a memória da guerra, mesmo desorganizada, da população paraguaia, a grande protagonista da resistência à invasão e à submissão do país. População das cidades e dos campos que sofria e seguira sofrendo duramente as sequelas da nova ordem imposta.

\section{0 fato, a memória e a versão}

Estanislao Zeballos retrata a sociedade paraguaia em transformações, não apenas quanto às interpretações sobre a guerra, determinadas por fortes contradições sociais, históricas, políticas, etc., que traspassavam o país. O que exige uma aproximação cuidadosa dos valiosíssimos relatos obtidos em 1887 e 1888, ou produzidos a seguir, para sua utilização como fontes dos sucessos a que se referiam.

Os depoimentos são versões sobre o passado, mediadas e traduzidas pela memória e conformadas pela situação do depoente no momento da locução, pela sintaxe da narrativa. Quanto mais distante dos fatos, mais a locução de uma memória é facilmente objeto de interferências e metamorfoses. As reconstituições de diálogos históricos, comuns na legenda histórica e historiografia da guerra grande, são também influenciadas pela autonomia tendencial das palavras, em relação, por um lado, ao depoente, no mo- 
mento da cedência da informação e, por outro, em relação ao locutor histórico, pretenso produtor original da fala.

Os diálogos históricos são retocados pela tradição quanto à sintaxe, sobrepondo-se as formas sintéticas às prolixas; as versões dramáticas às prosaicas; as locuções mais fônicas às menos fônicas, etc. Eles são retocados, mais ou menos conscientemente, pelas visões do depoente quando da locução e do registro dos diálogos. Épocas diversas produzem comumente relatos diversos, apresentados pelos mesmos depoentes, sobre os mesmos fatos. Os relatos históricos individuais tendem a adaptar-se às narrativas dominantes, constituídas e sacralizadas.

Zeballos transcreve literalmente o depoimento de Patrício Escobar sobre as palavras que o bispo Palacios teria dito, quando da comunicação por Solano López da descoberta da conspiração, no acampamento de San Fernando:

No es la clemencia lo que Vuestra Excelencia debe ofrecer. En este caso, la salud de Vuestra Excelencia y de la Patria exigen un castigo inmediato e inexorable y Vuestra Excelencia debe mandar ejecutar a degüello a todos los criminales (ZEBALLOS, 2015, p. 112).

Essas palavras diferem fortemente das versões de Centurión e Aveiro, que teriam estado presentes à reunião. Porém, os três mantinham-se em contato e certamente rememoravam os fatos, ensejando possíveis transferências e acomodações nas recordações de cada um. Centurión transcreve textualmente Palacios e enfatiza a proposta de execução imediata após a descoberta: "Que en su opinión el Mariscal debería disponer que fuesen pasados por las armas los cómplices, a medida que fuesen descubriéndose" (CENTURIÓN, 2010, p. 312). Aveiro refere-se à proposta de Palacios, sem se referir à reunião:

[...] se aproximaba el 24 de julio, natalicio del Mariscal [...]. El Obispo Palacios, tomando por pretexto esta proximidad de las fiestas, com repetición y en distintas reuniones de los fiscales y jefes allegados, decía al Mariscal que si la causa estaba tan bien averiguada [...] se diera por terminado el procedimiento, colgándose a todos los encausados (AVEIRO, 1998, p. 67).

Na primeira versão, pedia-se o fuzilamento, na segunda, o uso da forca. Em suas Memórias militares, Aveiro propôs sobre a conspiração: "Yo pienso que ha existido [...]" (AVEIRO, 1998, p. 67).

Zeballos não entrevistou, como pretendera, Silvestre Aveiro quando de sua visita a Asunción, o que enriqueceu e não empobreceu as fontes historiográficas. Publicadas apenas quando do centenário de Cerro-Corá, as valiosas Memórias militares de Aveiro foram escritas precisamente a pedido de Estanislao Zeballos. O autor escreveu em sua breve introdução:

Las páginas que siguen son mi única auténtica declaración sobre la guerra [...]. Digo declaración, por que fueron algo así cuando las escribí en 1880 [sic], respondiendo a un interrogatorio del Dr. Estanislao Zeballos, empeñado entonces en acumular datos para escribir una historia de dicha guerra (AVEIRO, 1998, p. 27).

Talvez o exemplo mais paradigmático de flutuação individual da memória seja o padre Fidel Maíz. Em 1918, anos após a declaração dada a Zeballos, foi publicado o libe- 
lo condenatório redigido pelos clérigos Justo Román e Fidel Maíz, em $1^{\circ}$ de dezembro de 1868, em Pykysyry, pedindo a suspensão de Palacios de sua alta função eclesiástica e sua morte. No documento, rogavam a Solano López, definido como "Cristo del Pueblo Paraguayo", a nomeação de um novo bispo, para não deixar "huérfana y viuda" a Igreja do país, praticamente sugerindo Maíz para o cargo (ROMÁN; MAÍZ, 1996, p. 73-95).

Em 7 de julho de 1889, na carta a Zeballos, desde Arroyos y Esteros, sua vila natal, Fidel Maíz descarrega sobre López as enormes responsabilidades que lhe eram imputadas pela participação nos julgamentos-execuções. Na longa missiva, refere-se ao mariscal como "tirano" - mais de vinte vezes -, "autocrata", "absolutista", "orgulhoso", "monstruo de la tirania", homem de "crueldad sin limites" e "desposeído ya de todo sentimento de humanidad", "Nerón de América". Para o padre Maíz, ele e os outros elevados colaboradores do mariscal seriam "funcionários" submetidos - como soldados à disciplina dos oficiais - às ordens peremptórias do tirano, em ambiente de terror que os acabrunhava com a permanente ameaça das "penas y morte" "contra aquellos" que pensavam de "otra maneira" que López..$^{22}$ Anos mais tarde, consolidado o lopizmo positivo no Paraguai, em nova pirueta, Maíz participaria da sacralização historiográfica de quem acusara, em 1888, como verdugo deplorável.

O bom sacerdote, já venerando ancião, escreveria sobre Solano López: "No hay figura que remplace al Mariscal López, figura de talla colosal, guerrero sin igual, que se alza imponiéndose a la admiración del mundo y a la gratitud de su patria".
Así es que, cualquiera que sean los errores de López, éste es una gran figura: EN ÉL SE ENCARNA LA PATRIA PARAGUAYA EN TODO LO QUE TIENE DE FERVOR, DE ENERGÍA, DE ELASTICIDAD... DE ETERNIDAD. [...] EL CULTO DE LÓPEZ, [... ] NO ES SINO EL CULTO DE LA PATRIA (MAÍZ, 1916, p. 126-132, grifo do autor).

\section{Abstract}

Using from the Estanislao Zeballos Archive Fund Juan Bautista Gill Aguinaga discusses Argentine politician's trajectory and its relationship to the war against Paraguay (1865-70). The proposals to produce a general history of the conflict and the reasons of its non non-completion are explored. The documentation produced by him on visits to Paraguay and his record of the development of pro-lopizta revisionists spirit in the country are also analyzed. The article addresses the problems posed by the direct and indirect oral testimony of protagonists on the war.

Keywords: Estanislao Zeballos. War of Paraguay. History and memory.

\section{Resumen}

A partir del Fondo Zeballos Estanislao, del Archivo Juan Bautista Gill Aguinaga, de próxima publicación, se discute el sentido de la trayectoria del importante político argentino de la Generación de 1880, y su relación con la guerra contra el Paraguay [1865-1870]. Se discuten las razones eventuales de la no finalización de su propuesta de producir una histo- 
ria general del conflicto. Se analiza la documentación producida por él en sus visitas a locales de combates y a Asunción en 1887 y 1888, y su testimonio del desarrollo, entonces, de un fuerte espíritu revisionista pro-lopizta en Paraguay. Se ocupa de los problemas planteados por el testimonio oral de los protagonistas, directos e indirectos, sobre esos sucesos.

Palabras clave: Estanislao Zeballos. Guerra del Paraguai. História y memória.

\section{Notas}

1 Agradecemos a gentil leitura da historiadora Maria José Becerra da Universidad Nacional de Cordoba, Argentina, e da linguista Florence Carboni, da Universidade Federal do Rio Grande do Sul, Brasil.

2 Parte do arquivo paraguaio de Estanislao Zeballos foi comprada pelo intelectual paraguaio e rico proprietário Juan Bautista Gill Aguinaga (1910-1982) e legada, mais tarde, ao Estado paraguaio. Devido a financiamento do governo argentino, foi empreendida a publicação dessa documentação, em livro, a ser apresentada em 2015 (BREZZO, 2015).

3 Sobre as primeiras histórias da guerra escritas por combatentes e contemporâneos brasileiros, cf. (GAY, 1867; MADUREIRA, 1870; DIAS, 1870; TAUNAY, 1871; SILVA, 1877; JOURDAN, 1890).

4 Carta de Fidel Maíz a Estanislao Zeballos, Arroyos y Esteros, 7 de julho de 1889. Juan Bautista Gill Aguinaga. Fondo Estanislao Zeballos. Carta del Padre Fidel Maíz a Estanislao Zeballos. Carpeta $\mathrm{N}^{\circ} 122$.

5 ZEBALLOS, Estanislao. Informes de la Señora Concepción Domecq de Decoud, Asunción, 1888, Segundo viaje al teatro de la Guerra. Archivo Juan Bautista Gill Aguinaga. Fondo Estanislao Zeballos. Carpeta No 128 (ZEBALLOS, [2015], p. 85).

6 ZEBALLOS, Estanislao. Viaje al Teatro de la Guerra del Paraguay Abril de 1887. 14 de abril. Archivo Juan Bautista Gill Aguinaga. Fondo Estanislao Zeballos (ZEBALLOS, [2015], p. 245-54).

7 Declaraciones del Dr. Stewart súbdito inglés Cirujano Mayor del Ejército del Paraguay. Archivo Juan Bautista Gill Aguinaga. Fondo Estanislao Zeballos. Carta de Guillermo Stewart a Estanis- lao Zeballos. Carpeta No 124 (ZEBALLOS, [2015], p. 80).

8 Carta de Juana C. de Resquín a José Mernes. Villa Concepción, 12 de abril de 1888. Fondo Estanislao Zeballos. Carpeta No 149 (ZEBALLOS, [2015], p. 161).

9 Carta de Fidel Maíz, Arroyo y Esteros, 7.7.1889, a Estanislao Zeballos, Buenos Aires, Archivo Juan Bautista Gill Aguinaga. Carpeta 122 (ZEBALLOS, [2015], p. 61).

10 ZEBALLOS, Estanislao. Segundo Viaje al Teatro de la Guerra. Informes del señor presidente de la República, General Don Patricio Escobar, que hizo toda la guerra hasta la muerte de López. Archivo Juan Bautista Gill Aguinaga. Fondo Estanislao Zeballos. Informes del general Patricio Escobar. Carpeta n 130 (ZEBALLOS, [2015], p. 111).

11 Carta de Fidel Maíz a Estanislao Zeballos, Arroyos y Esteros, 7 de julho de 1889. Fondo Estanislao Zeballos (ZEBALLOS, [2015], p. 61).

12 Carta de Fidel Maíz a Estanislao Zeballos, Arroyos y Esteros, 7 de julho de 1889. Fondo Estanislao Zeballos (ZEBALLOS, [2015], p. 61).

13 Anexo à carta de Fidel Maíz, Arroyo y Esteros, 7.7.1889, a Estanislao Zeballos, Buenos Aires, Archivo Juan Bautista Gill Aguinaga. Carpeta 122. Fondo Estanislao Zeballos (ZEBALLOS, [2015], p. 61).

14 Anexo à carta de Fidel Maíz, Arroyo y Esteros, 7.7.1889, a Estanislao Zeballos, Buenos Aires, Archivo Juan Bautista Gill Aguinaga. Carpeta 122. Fondo Estanislao Zeballos (ZEBALLOS, [2015], p. 61).

15 Pedro Duarte. Recuerdos del General Pedro Duarte comunicados especialmente a Estanislao Zeballos. Fondo Estanislao Zeballos (ZEBALLOS, [2015], p. 92).

16 ZEBALLOS, Estanislao. Segundo Viaje al Teatro de la Guerra 1888. Varias noticias recogidas en la Asunción. Archivio Juan Bautista Gill Aguinaga. Carpeta $N^{\circ} 128-1$. Fondo Estanislao Zeballos (ZEBALLOS, [2015], p. 61).

17 ZEBALLOS, Estanislao. Segundo Viaje al Teatro de la Guerra 1888. Varias noticias recogidas en la Asunción. Archivio Juan Bautista Gill Aguinaga. Carpeta $N^{\circ} 128-1$. Fondo Estanislao Zeballos (ZEBALLOS, [2015], p. 61).

18 ZEBALLOS, Estanislao. Memorias del Doctor José Segundo Decoud 1888 Asunción. Segundo viaje al teatro de la Guerra Informes de Doctor José Segundo Decoud Ministro de Relaciones Exteriores del Paraguay. Archivio Juan Bautista Gill Aguinaga. Fondo Estanislao Zeballos. Informes 
de José Segundo Decoud. Carpeta No 125 (ZEBALLOS, [2015], p. 83).

19 ZEBALLOS, Estanislao. Segundo Viaje al Teatro de la Guerra 1888 (ZEBALLOS, [2015], p. 43).

20 ZEBALLOS, Estanislao. Segundo Viaje al Teatro de la Guerra 1888 (ZEBALLOS, [2015], p. 43).

${ }^{21}$ ZEBALLOS, Estanislao. Segundo Viaje al Teatro de la Guerra 1888 (ZEBALLOS, [2015], p. 431).

22 Carta de Fidel Maíz, Arroyo y Esteros, 7.7.1889, a Estanislao Zeballos, Buenos Aires, Archivo Juan Bautista Gill Aguinaga. Carpeta No 122 (ZEBALLOS, [2015], p. 61).

\section{Referências}

AGUINAGA, Juan B. Gill. La Asociación Paraguaya en la Guerra de la Triple Alianza. Asunción: Servilibro, 2011.

AVEIRO, Silvestre. Memorias militares. Asunción: El Lector, 1998.

BEVERINA, Juan. La guerra del Paraguay: las operaciones de la guerra en territorio argentino y brasileño. Buenos Aires: Biblioteca del Oficial, 1933. $6 \mathrm{v}$.

BORMANN, Jose Bernardino. História da guerra do Paraguai. Curitiba: Paranaense Jesuino Lopes, $1897.3 \mathrm{v}$.

BREZZO, Liliana M. La guerra de la Triple Alianza en la primera persona de los vencidos: el hallazgo y la incorporación de la Sección Estanislao S. Zeballos del Ministerio de Defensa de Paraguay. Anuario de la Escuela de Historia - Facultad de Humanidades y Artes - UNR; Lugar: Rosario; Año: 2011, p. 201-220.

La guerra del Paraguay a través de la memoria de sus actores: el proyecto historiográfico de Estanislao Zeballos. Nuevo Mundo, Mundos Nuevos Colloques, Paris, févr. 2006. Disponível em: <http://nuevomundo.revues. org/1677>. Acesso em: 17 ago. 2014.

. (Org.). La Guerra del Paraguay en primera persona. Testimonios inéditos. Fondo Estanislao Zeballos. Asunción: Tiempo de Historia, 2015.
CENTURIÓN, Juan Crisóstomo. Memorias o reminiscencias históricas sobre la guerra del Paraguay. Asunción: El Lector, 2010.

CERVO, Amado Luiz; BUENO, Clodoaldo. A politica externa brasileira (1822-1985). São Paulo: Ática, 1986. (Série Princípios).

COSTA, Francisco Felix Pereira da. História da guerra do Brasil contra as repúblicas do Uruguay e Paraguay. Contendo considerações sobre o exército do Brasil e suas campanhas no Sul até 1852. Campanha do Estado Oriental em 1865. Marcha do Exército pelas Províncias argentinas. Campanha do Paraguay. Operações do Exército e da Esquadra. Acompanhada de juízo crítico sobre todos os acontecimentos que tiveram lugar nesta memorável campanha. Rio de Janeiro: Guimarães, 1870-1871. 4 v.

CUNHA, Euclides da. Os sertões: campanha de Canudos. 4. ed. Rio de Janeiro: Francisco Alves; Paris: Aillaud, Alves, 1911.

DALLA-CORTE, Gabriela. El Estado nacional en el control económico del Gran Chaco. La unidad de los intereses políticos y empresariales de Estanislao Zeballos y Carlos Casado del Alisal. In: DALLA-CORTE, Gabriela et al. (Coord.). Homogeneidad, diferencia y exclusión en América. Barcelona: Universidad de Barcelona, 2006.

Felisa Jordán. La madre de Estanislao Zeballos. Prácticas Asociativas, Espacio Público y Proyección Femenina en Argentina (1870-1880). Revista Digital de la Escuela de Historia, UNR, Rosario, a. 3, n. 5, p. 11-34, 2011. Disponível em: <http://web.rosario-conicet. gov.ar/ojs/index.php/RevPaginas/article/ view/107>. Acesso em: 25 jul. 2014.

Una sociedad en red: prácticas asociativas, espacio público y proyección femenina en Argentina (1870-1880). In: BONACCORSI, Nélida; LAGUNAS, Cecilia (Ed.). Hacia una redefinición del concepto patrimonio cultural. La inclusión de las Mujeres, Editorial de la Universidad Nacional del Comahue, 2009. Disponível em: <http://dallacorte.files.wordpress. 
com/2013/06/2009-dalla-corte-zeballos.pdf>. Acesso em: 28 jul. 2014.

DE MARCO, Miguel Angelo. Dos escritos juveniles de Estanislao S. Zeballos. Temas de Historia Argentina y americana, Buenos Aires, n. 14, p. 217-244, enero-jun. 2009. Biblioteca digital da Universidad Católica Argentina. Disponível em: <http:/ / bibliotecadigital.uca.edu.ar/repositorio/revistas/dos-escritos-juveniles-estanislao-zeballos.pdf>. Acesso em: 6 ago. 2014.

DIAS, Satyro de Oliveira. O Duque de Caxias e a Guerra do Paraguay: Estudo Crítico-Histórico. Bahia: Diário, 1870.

ÉBÉLOT, Alfred. Adolfo Alsina y la ocupación del Desierto. Relatos de la frontera. Buenos Aires: El Elefante Branco, 2008.

ESTEVES, Gomes Freire. História Contemporánea del Paraguay. Asunción: El Lector, 1996.

FRAGOSO, Gal. Augusto Tasso. História da Guerra entre Tríplice Aliança e o Paraguai. Rio de Janeiro: Imprensa do Estado Maior do Exército, $1934.5 \mathrm{v}$.

GARMENDIA, José Ignacio. Recuerdos de la guerra del Paraguay. Buenos Aires: Jacob Peuser, 1883-1884. 2 v.

GAY, João Pedro. Invasão paraguaia na fronteira brasileira do Uruguai: desde seu princípio até o fim (de 10 de junho a 18 de setembro de 1865). Rio de Janeiro: Tip. Imperial e Constitucional de J. Villeneuve, 1867.

HEINSFELD, Adelar. Falsificando telegramas: Estanislao Severo Zeballos e as relações Brasil-Argentina no início do século XX. In: ENCONTRO ESTADUAL DE HISTÓRIA - VESTÍGIOS DO PASSADO, Seção Rio Grande do Sul, 9, 2008, Porto Alegre. Anais... Porto Alegre: ANPUH, 2008. p. 1-10. Disponível em: <http:/ / eeh2008.anpuh-rs.org.br/resources/content/ anais/1211228384_ARQUIVO_FalsificandoTelegramas.pdf>. Acesso em: $1^{\mathrm{o}}$ jul. 2014.
HERRERA, Luís Alberto de. El drama del 65. La culpa mitrista. Montevideo: A. Barreiro y Ramos, 1927.

JOURDAN, E. C. Guerra do Paraguay. Rio de Janeiro: Laemmert, 1890.

LACOSTE, Pablo; ARPINI, Adriana. Estanislao Zeballos, La politica exterior argentina, la ideología racista de la elite ilustrada rioplatense y la reforma universitaria de 1918. Revista Universum, Universidad de Talca, Chile, a. 17, p. 125-146, 2002. Disponível em: <http:/ / www.universum.utalca.cl/contenido/index-02/lacoste.pdf>. Acesso em: 2 ago. 2014.

LASSERRE, Dorothéa Duprat de. Memórias de Dorothéa Duprat de Lasserre. Versão e notas J. Arthur Montenegro. Rio Grande do Sul: Reis Bastos; Trocadero, 1893.

MADUREIRA, Cel. Antônio de Sena. Guerra do Paraguai: resposta ao sr. Jorge Thompson, autor da "Guerra del Paraguay" e aos anotadores argentinos D. Lewis e A. Estrada. Rio de Janeiro: Typographia do Imperial Instituto Artistico, 1870.

MAESTRI, Mário. A guerra contra o Paraguai: história e historiografia: da instauração à restauração historiográfica (1871-2002). Nuevo Mundo, Mundos Nuevos, Colloques, Paris, não paginado, mars 2009. Periódico on-line. Disponível em: <http://nuevomundo.revues. org/55579>. Acesso em: 10 jun. 2015.

. Cisnes negros: 1910: a revolta dos marinheiros contra a chibata. 3. ed. Porto Alegre: FCM, 2015.

Tasso Fragoso e a guerra da Tríplice Aliança. História e ideologia. O Olho da História, Salvador, BA, n. 18, não paginado, jul. 2012. Disponível em: <http://oolhodahistoria.org/n18/ artigos/maestri.pdf>. Acesso em: 10 jun. 2015.

MAÍZ, Fidel. Desagravio. Asunción: La Mundial, 1916. 
PAGNI, Florencia; CESARETTI, Fernando. La metamorfosis de Francisco Solano López. Crónica de la larga operación histórica que transformó a un individuo nefasto para su pueblo en el prócer paradigmático de la nación. Blogue grupo Efefe, Grupo de Estudo de História. 2007. Disponível em: <http://grupoefefe.blogspot. com.br/2007/09/la-metamorfosis-de-francisco-solano.html>. Acesso em: 10 jun. 2015.

POMER, Léon. Cinco años de guerra civil en la Argentina (1865-1870). Buenos Aires: Amorrorte, 1986.

RODRÍGUEZ, F. Estanislao S. Zeballos: un desierto para la nación. Relics \& Selves: Articles. Portal Birkbeck University of London. c2015. Disponível em: <http://www.bbk.ac.uk/ ibamuseum/texts/Rodriguez01.htm>. Acesso em: 10 jun. 2015.

ROLÓN, Oscar Bogado. Sobre cenizas. Construcción de la Segunda República del Paraguay (1869-1870). Asunción: Intercontinental, 2011.

ROMÁN, Justo; MAÍZ, Fidel. Campamento de Pykysyry, diciembre $1^{\circ}$ de 1868 . In: GODOY, Juan Silvano. El fusilamiento del Obispo Palacios y los tribunales de sangre de San Fernando. Documentos históricos. Asunción: El Lector, 1996. ( $1^{\mathrm{a}}$ edição em folhetim, El Liberal, de Asunción; em livro, 1918).

SÁNCHEZ, Santiago Janvier. Nacionalidad e inmigración en el pensamiento de Estanislao Zeballos (1883-1912). Temas de Historia Argentina y americana, Buenos Aires, n. 15, p. 223-258, jul.-dic. 2009. Biblioteca digital da Universidad Católica Argentina. Disponível em: <http:// bibliotecadigital.uca.edu.ar/repositorio/revistas/nacionalidad-inmigracion-pensamiento-estanislao-zeballos.pdf>. Acesso em: 2 ago. 2014.

SCHNEIDER, Louis. A guerra da Tríplice Aliança contra a República do Paraguai (1864-1870). Anotado por José M. da S. Paranhos. Rio de Janeiro: Garnier, 1902. 2 v.
SILVA, Teotônio Meirelles. O exército brasileiro na Campanha do Paraguai: resumo histórico. Rio de Janeiro: O Globo, 1877.

TAUNAY, Alfredo d' E. La Retraite de Laguna: Épisode de la Guerre du Paraguay. Rio de Janeiro: Typographia Nacional, 1871.

THOMPSON, George. La guerra del Paraguay: acompañada de un bosquejo histórico del país y con notas sobre la ingeniería militar. Buenos Aires: Americana, 1869.

ZEBALLOS, E. S. La conquista de quinze mil léguas: estúdio sobre la traslación de la fronteira sul de la República al rio Negro. Dedicado a los jefes y oficiares del Ejercito Expedicionário. Buenos Aires: La Prensa, 1878.

La guerra del Paraguay en primera persona. Testimonios inéditos. Fondo Estanislao Zeballlos. Ed. Brezzo, L. Asunción: Tiempo de Historia, [2015].

. La nationalité au point de vue de la législation comparée et du droit privé humain. Paris: Sirey, 1914-1919. $5 \mathrm{t}$. 